\title{
Techniques and Strategies Utilized for Vocabulary Acquisition: the necessity to design a multifaceted framework with an instructionally wise equilibrium
}

\author{
Mohammad Mohseni-Far, M.A. \\ Shahid Chamran University, \\ Ahwaz, Iran
}

Received: 18-12-06 / Accepted version: 3-04-07

ISSN: $1697-7467$

\begin{abstract}
The purpose of this paper is to pore attentively inquiry over vocabulary learning/acquisition strategies and techniques within the scope of second/foreign language. In doing so, the research is intended to zoom in profoundly on the variables connected to lexical knowledge and accordingly launch rather comprehensive framework taking in and accounting for mostly important strategies and pertinent factors within the vocabulary acquisition context. To begin with, a sketch taking in four salient variables which are learner, task, context, and strategies is introduced to pay meticulous heed to the review. Moreover, previously-conducted research along mentioned variables is critically considered. In particular, the analysis zeroes in deeply on task-dependent strategies for this variable is much more tangible and yet possesses practically more pedagogical implications. In lieu of seeking the superlative strategies and techniques that bring into being the paramount outcomes, the investigator implies the relative efficiency of each single strategy and technique. The organic notion underlying this study is that the most effective and efficient lexical development will occur in multifaceted curriculums that attain a pedagogically well-reasoned symmetry between explicit and implicit activities for L2 learners at all levels of their progress.
\end{abstract}

Keywords: vocabulary acquisition/learning, strategies and techniques, lexical knowledge, lexical development.

RESUMEN: El objetivo de este artículo es estudiar detalladamente las estrategias y técnicas de aprendizaje/adquisición de vocabulario dentro del campo de las segundas lenguas o lenguas extranjeras. Con este propósito, el estudio focaliza exhaustivamente sobre las variables relacionadas con el conocimiento léxico y estable un marco teórico exhaustivo considerando las estrategias más importantes y los factores más pertinentes para el aprendizaje de vocabulario. Para empezar, se introduce un bosquejo sobre las cuatro variables más relevantes como son el aprendiz, la tarea, el contexto y las estrategias. Además, consideramos de manera crítica investigaciones llevadas a cabo previamente sobre las mismas variables. En particular, el análisis se centra de forma profunda en estrategias dependientes de la tarea para esta variable. Así, es mucho más tangible y posee más implicaciones pedagógicas. En lugar de buscar las estrategias y técnicas superlativas que representan los resultados más sobresalientes, el investigador relaciona 
la eficacia relativa de cada una de las estrategias y técnicas. La noción orgánica que subyace a este estudio es que el desarrollo léxico más efectivo y eficiente tiene lugar siempre en currículos multifacéticos que logran una simetría pedagógica razonada entre las actividades explícitas e implícitas para los aprendices de L2 en todos los niveles de su progreso.

Palabras clave: adquisición/aprendizaje de vocabulario, estrategias y técnicas, conocimiento léxico, desarrollo léxico.

\section{INTRODUCTION}

Vocabulary acquisition is considered as an integral and fundamental area of language teaching/learning by linguistic researchers. Psychologists, linguists and language teachers have been interested in vocabulary learning strategies for a long time. They have tried to understand the role of the lexicon in language learning and communication. Accordingly the increased attention to vocabulary teaching has become more important. In particular, during past fifteen years, the field of second language acquisition has seen renewed interest in vocabulary learning and acquisition. There are many dimensions to vocabulary acquisition, as reflected in the multitude of different areas of research being done on the topic.

One way to investigate overall task of vocabulary learning/acquisition is through the distinction between knowing a word and using a word. In other words, the purpose of vocabulary learning should include both recalling words and the ability to apply them automatically in a wide range of language contexts when the need emerges. Vocabulary learning strategies, theretofore, should incorporate strategies for "using" as well as "recognizing and knowing" words.

Another way to view vocabulary learning is to take it as a process of interconnected subtasks. When learners first encounter a new word, they might guess its meaning and usage from accessible tokens. Some learners might resort to consult dictionary. Others might write down notes along the margins, between lines, or on a separate vocabulary notebooks. Some learners will take advantage of simple rote repetition to commit the word to memory. Some would even attempt to use the word enthusiastically in a real context. Each of these task stages demands metacognitive decision, choice, and deployment of cognitive strategies for vocabulary learning. And each technique a learner puts to use will determine to a large degree how and how well a new word is learned/acquired.

This article aims to provide a digest of recent research on vocabulary acquisition and to pinpoint areas that need further exploration. To this end, the researcher centers on one particular area in depth, i.e., vocabulary learning strategies. In so doing, it attempts to synthesize for the reader the major and recent findings of research into vocabulary learning and acquisition, outline each of the main areas of research on the subject matter.

\section{Critical Review of Related Literature}

\subsection{Background}

Vocabulary acquisition is one of the significant issues being always attached by great importance particularly in recent years. Effective second language vocabulary acquisition is 
particularly important for English as a foreign language (EFL) learners who frequently acquire impoverished lexicons despite years of formal study (Hunt \& Beglar, 2005:1). Vocabulary learning is central to language acquisition, whether first, second or foreign. Today's language teachers and researchers have realized the important role of vocabulary in different pedagogical tasks. There is no doubt that virtually all second language learners and their teachers are well aware of the fact that learning a second language (L2) involves the learning of large numbers of words (Avila \& Sadoski, 1996; Laufer \& Hulstijn, 2001), but how to accomplish this task is often of considerable concern to them (Ott, Blake \& Butler, 1976:37). How vocabulary is acquired and what the most efficient means are to promote effective acquisition have been worthwhile lines in the field of second language acquisition (De La Fuente, 2002:82). In sum, they all place emphasis on the fact that mastery of vocabulary is an essential component of second language acquisition.

Irrespective of the significance of the lexical knowledge and vocabulary acquisition, the techniques and strategies recommended in this field are somewhat challenging ((MohseniFar, 2006:149). Although researchers and language teachers are becoming more and more convinced that vocabulary knowledge constitutes an essential part of competence in a second or foreign language, no comprehensive theories have been proposed up to now that try to explain foreign language growth in terms of lexical development (Bogaards, 2001:321). Although the amount of empirical research on vocabulary acquisition is expanding, consensus is absent over issues such as the conceptualization of the process by which vocabulary acquisition betides, the importance of context use for acquiring vocabulary, and the amount to which students build up specific strategies for vocabulary learning during their language studies. According to Newton (2001:30), encounters with unfamiliar vocabulary are among the obvious and inevitable challenges faced by language learners using the target language in communication outside the classroom, whether for work; travel, or recreation, when using the media, or in academic contexts.

The acquisition of a new lexical item is a complex process. Ellis, Tanaka and Yamazaki (1994:457) argue that vocabulary acquisition involves discovering the frequency with which the item is used in speech and writing, its situational and functional uses, its syntactic behavior, its underlying form and the forms that can be derived from it, the network of associations between it and other items, its semantic features and, of course, the various meanings associated with the item. As a result, research on L2 vocabulary acquisition encompasses a number of different and diverse subareas. Put another way, how words are stored in the mental lexicon, automaticity of retrieval, the role of vocabulary in reading comprehension, ..., the role of background knowledge, the implications for L2 vocabulary acquisition for L1 vocabulary research, how words are learned in context and other strategies for reading in L2 (Chun \& Plass, 1996:184).

In order to conduct the research in a more systematic and logical way, the researcher takes prominent variables such as learner, task, context and strategy into account. These four factors are primarily introduced and defined, then in subsequent parts they are dealt with more details. Having taken these important variables into consideration, the investigator also tries to shed significant light on major issues and comments concerning each variable. 


\subsection{Learner, task, context and learning strategies}

When a learner intends to explore a relatively challenging task, s/he adopts certain strategies to solve the problem. This problem-solving procedure is bound to the learning context where the problem is being tackled. Language learning in general and vocabulary acquisition in particular are taken as such problem-solving tasks at different levels of complexity. The strategies a learner exercise and the effectiveness of these strategies very much depend on the learner him/herself (e.g., attitudes, motivation, prior knowledge, topic familiarity), the learning task at hand (e.g., type, complexity, difficulty, and generality), and the learning milieu (e.g., the learning culture, the affluence of input and output opportunities). The effectiveness of these strategies utilized by the learner is under question as well.

Learner, task, context, and strategy are interrelated and work together to form the scaffold of learning/acquisition. Moreover, an analysis of learning strategies will never be complete without discerning the learner, task and context configuration of the particular learning situation. Some strategies are more learner-dependent, some are more task- dependent, and others are more context-contingent.

\subsubsection{Learner}

The variable Learner needs to be discussed from different perspectives. The leaner brings to the language learning situation a wide spectrum of individual differences that will influence the learning rate and the ultimate learning result ( $\mathrm{Gu}, 2003: 2)$. The most widely reported learner factors include gender, language aptitude, intelligence, prior knowledge, motivation, self-concept/image, personality, and cognitive and learning style. Motivation, emotion, and socio-cultural factors may affect the way in which human process information (Laufer \& Hulstijn, 2001:7). The noted learner-dependent factors are stable and mark out to a large context how a learner handles a task.

\subsubsection{Task}

The conception of the learning task incorporates materials being learned (such as genre of a piece of reading) as well as the end the learner is attempting to achieve by using these materials (such as remembering, comprehending, or using language).Task can be defined as an activity or action which is carried out as a result of processing or understanding language. Laufer and Hulstijn (2001:17) refine the meaning of task in the field of the vocabulary acquisition in particular as "an activity in which: meaning is primary". A learning task is the ultimate artifact in learner's mind, therefore, in order to test a person's lexical knowledge, tasks such as reading and comprehension from different perspectives, writing original sentences, writing a composition and creative writing can be implemented.

\subsubsection{Context}

It is necessary to distinguish between two types of context. First, learning context which refers to the "learning environment and includes the teachers, the peers, the classroom climate or ethos, the family support, the social, cultural tradition of learning, the curriculum, and the 
availability of input and output opportunities" (Gu, 2003:2). Second, language context which refers to the textual or discoursal place in which a particular word or structure can be found. The latter has been attached by great importance among the researchers and accordingly it will go through much more investigation and in more details within this study. In support of the significance of context, Lawson and Hogben (1996:106) suggest that from a psychological as well as a linguistic point of view, underlying the first guideline would be that vocabulary must be learned in context. Activities and reading materials that present words in meaningful contexts may contribute to vocabulary gains and are valued highly by students (Zimmerman, 1997:136).

\subsubsection{Strategy}

A learning strategy encompasses a series of activities and efforts a learner makes to facilitate the completion of a learning task. A technique initiates when the learner examines the task, the situation, and what is available in his/her own mind. The learner then goes on to select, deploy, monitor, and weigh up the effectiveness of this activity, and decides if s/ he needs to revise the plan and action. In fact, theorists now place considerable stress on the importance of foreign language students' developing autonomous learning strategies (Favretti, Silver, Tamburini \& Gasser, quoted in Lawson \& Hogben, 1996:106). Contextual guessing, skillful use of dictionaries, note-taking, paying attention to word formation and contextual encoding are some strategies normally applied by learners.

\subsection{Task-dependent vocabulary learning strategies}

Most of the empirical researches on vocabulary learning strategies in a second language have focused on different sub-tasks of vocabulary learning. Fewer studies can be found on learner-related vocabulary learning strategies.

\subsubsection{Guessing}

The premise under this line of research is the belief that vast majority of words in L1 come from extensive and manifold exposures through the use rather than direct instruction, and therefore vocabulary learning in a second language should trail the same way. A number of topics have often been put forward in the literature: guessing leading to vocabulary learning, inference from context, exposures needed to learn a word, and incidental (implicit) vocabulary learning and intentional (explicit) learning one, each of these questions is critically dealt with below.

\subsubsection{Guessing ending in vocabulary learning}

One of the strategies most often discussed in the literature is guessing word meaning from the clues made available by the context. Factors that affect the likelihood of success in inferencing include a context rich enough to provide adequate clues to guess a word's meaning (Celce-Murcia, 2001:290). Put another way, the unknown word to be guessed has to have plenty of comprehensible supporting context (Nation \& Meara, 2002:44). In order to discuss 
this issue from a pedagogical standpoint, it is better to use the technical alternative "inferring" meaning from the context instead of "guessing". It is also obvious that context and inferring meaning are interconnected and accordingly need to be studied in depth.

\subsection{Inference from context}

One difficulty in this area of research is that there is no standard characterization of what is intended by context. In its broadest sense, of course, context may be said to comprise all the perceived phenomena that accompany the process of a given stimulus, including the physical surroundings in which learning take place (Prince, 1996:479). Using the meanings of words together within the whole meaning of the sentence is the deepest level of processing and ensures the best memory (Cook, 1991:36). Crucial to inferring meaning from context is the degree to which context unveils word meaning. This degree is restricted by the student's own background knowledge and constraints in the text itself. Hence, both the teachers and the students must be aware that context functions to restrict meaning as well as to reveal it.

Some contexts do not provide a lot of information about a word, but some others provide some information that can take knowledge of the word forward. Shu, Anderson and Zhang (1995:79) suggest that significant learning from context is evident only when unfamiliar words appeared repeatedly. When a context is rich enough, it will be sufficient to allow a learner to infer the full word meaning. On the other hand, if a context is too simple to understand, then no vocabulary acquisition takes place. For example, at superior levels of proficiency, and when reading for comprehension - rather than to explicitly learn the meaning of unfamiliar words- the context may be easily understood without having to determine the meaning of every unfamiliar word (Pulido, 2003:241). Pulido (2004:472) also states that words that may be easily guessed in the course of reading may not be better retained because of the lack of a need to allocate sufficient attention to the connection between the new word form and its meaning.

Aside from the richness of context, prior/background knowledge (topic familiarity) and reader's vocabulary proficiency level are of great significance. There are many accounts in the psychological and SLA literature that greater levels of background knowledge and expertise in a given subject matter result in the efficiency of attentional allocation during reading, enable richer analyses and textual interpretations, and, in turn, superior memory performance (Pulido, 2003:236). In simple words, a reader is more successful at lexical inferencing when $\mathrm{s} / \mathrm{he}$ is aware of the topic. Since activation of appropriate knowledge structures stored in long-term memory is necessary to construct and integrate meaning successfully across discourse, it stands to reason that it will also have a strong bearing on the construction of meaning at the textual level. As a result, a text recall is enhanced when learners possess and utilize the appropriate background knowledge.

The other significant issue is a reader's vocabulary proficiency level. The stronger vocabulary a reader has, the better he is able to understand the text that he interacts with (Chin, 1999:1). In an experiment, Prince (1996:481) comes to the conclusion that advanced learners will make more efficient use of context than weaker learners, both during study phase and during recall.

In sum, contextual vocabulary acquisition is the active, deliberate acquisition of a meaning for a word in a text by reasoning from textual clues and prior knowledge, including language 
knowledge/proficiency level and topic familiarity. Second language (L2) learners in general, due to their inadequate grasp of target language [language knowledge] are less effective guessers and less effective incidental learners of English vocabulary (Gu, 2003:4).

\subsubsection{Exposures needed to learn a word}

It is clear that the frequency of occurrence of the unknown words in the text has a significant impact on the retention of word meaning. There exists a main reason that reappearance of a word will strengthen the form-meaning connection in the reader's mental lexicon. In a more technical experiment by Hulstijn, Hollander and Greidanus (1996:327) support was found for the hypothesis that frequency of occurrence will foster incidental vocabulary learning more when advanced second language (L2) readers are given the meanings of unknown words through marginal glosses or when they look up meanings in a dictionary than when no external information concerning unknown words' meaning is available.

It is rather complicated task to mention the precise or relative number of words and accordingly exposures in a text to learn a word. In addition, the number of exposures needed for mastery of a new word lies in many factors such as the salience of the word in the context, the richness of contextual clues, the learner's interest and his/her existing repertoire of vocabulary.

\subsubsection{Incidental (implicit) vs. Intentional (explicit) vocabulary learning}

In general, knowledge can be gained and represented either implicitly or explicitly and both contribute to language learning. There exists a central debate emerging from the studies dealt with whether effective vocabulary learning should give attention to explicit or implicit vocabulary learning.

In implicit vocabulary learning students engage in activities that focus attention on vocabulary. Incidental vocabulary learning is learning that occurs when the mind is focused elsewhere, such as on understanding a text or using language for communicative purposes (Celce-Murcia, 2001:289). From a pedagogically-oriented perspective, the goal of explicit teaching is "to lead learner's attention", whereas the aim of an implicit focus on form is "to draw learner's attention". Moreover, individual tasks can be located along an explicit or implicit continuum, and complex tasks may combine both explicit and explicit subtasks. From a cognitive psychological perspective, explicit learning can be contextualized as a conscious searching, building and testing of hypotheses and assimilating a rule following explicit instruction, whereas implicit learning is characterized by the automatic abstraction of the structural nature of the material arrived at from experience of instance (Hunt \& Beglar, 2005:3).

While definitions begin to clarify explicit and implicit learning, questions remain concerning what features of vocabulary and grammar are best learned explicitly or implicitly and how these processes occur. In addition to distinguishing between explicit and implicit instruction, it is also necessary to consider which is more effective for promoting the acquisition of vocabulary knowledge. In fact, there is evidence in recent studies of second language learners that a combined approach is superior to a single learning method. Most researchers recognized that a well-structured vocabulary program needs a balanced approach that includes explicit teaching together with activities providing appropriate contexts for incidental learning (Celce- 
Murcia, 2001:286). Hunt and Beglar (2005:3) in their framework also highlight that the most efficient learning involves a carefully selected combination of both explicit and implicit instruction and learning.

It should be finally noted that the most important explicit lexical instruction and learning strategies include lexis (word lists), using dictionaries and inferring from context, while the implicit approach primarily and basically involves students in meaning-focused reading. In the preceding sections, inferring from context was discussed. Now, the role of dictionary and then meaning-focused reading will be studied.

\subsubsection{Dictionaries}

Researchers are interested in investigating the part that dictionaries play in the learning of second language vocabulary. The disputation of the kind of dictionaries to be used in the foreign language classroom, and what dictionaries, if at all, should be used has always been an on-going one amongst language instructors and lexicographers. Presently, there is a prevalent view that EFL teachers should discourage students from consulting dictionaries because students' extensive dictionary use can lead to word for word reading (Chin, 1999:3).

Three types of dictionaries are available: bilingual, monolingual, and bilingualized, and these can be found in either paper or electronic form. Both bilingual and monolingual dictionaries have their unique strong points and weaknesses for developing vocabulary knowledge.

Apart from short and easy-to-understand definitions of bilingual dictionaries, the strengths of them are: they can improve the reading comprehension of lower proficiency L2 learners, they assist vocabulary learning at all levels of proficiency (Hunt \& Beglar, 2005:12). The bilingual dictionaries 1) encourage translation 2) foster one-to-one precise correspondence at word level between two languages 3 ) fail to describe adequately the syntactic behavior of words (Gu, 2003:8).

In contrast, monolingual learners' dictionaries can be used to build and elaborate learner's vocabulary knowledge using up-to-date and reliable sentence examples drawn from corpus data that provide information about meaning, grammar and usage (Hunt \& Beglar, 2005:12). The monolingual entry can generally provide more detailed and precise information about idiomatic usage, common collocations, connotations, and register (Laufer \& Hadar, 1997:189).

Since a combination of good features of both types of dictionaries is attainable, there is considerable interest in the new bilingualized compromise dictionaries. A bilingualized entry typically includes: L2 definitions, L2 sentences information or L1 synonyms of the headword. These hybrid and fused dictionaries essentially provide translations in addition to the good features of monolingual dictionaries.

Using bilingualized dictionaries is more efficient than using separate bilingual and monolingual dictionaries, and they are more flexible because beginning and intermediate learners can rely on the L1 translation and advanced learners can concentrate more on L2 part of the entry (Laufer \& Hadar, 1997; Gu, 2003; Hunt \& Beglar, 2005).

The above types of dictionaries are also available in various electronic forms (software, pocket electronic and online dictionaries). It is obvious that electronic dictionaries (E-dictionaries) are easier and more convenient to use than printed dictionaries. They frequently permit the learners to search multiple sources (grammar, text usage as well as thesaurus), save and review words and definitions. Some e-dictionaries offer advanced searches, provide multimedia 
annotations, such as illustrations and video that assist in reading comprehension and vocabulary learning (Chun \& Plass, 1996:185).

Regardless of the dictionary chosen, learners require learning to use it effectively. Perhaps we have become more unconvinced about a single most appropriate dictionary format, perhaps we are more cautious about stereotyped statements on which dictionary is good for a learner, it is worth noting that more research is needed on what real dictionary users do in real situations of dictionary look-up. In order to use a dictionary effectively, what exactly learners do and how their dictionary strategies influence their learning results should be taken into consideration as well.

\subsubsection{Meaning-focused reading}

Reading is one of the most important ways that learners gain lexical knowledge incidentally. Recent developments in lexical semantics tell us a lot about vocabulary learning. The zoom on meaning-focused reading will result in incremental increases in vocabulary size, the elaboration of lexical knowledge and development of reading fluency. Zimmerman (1997:123) believes that a considerable amount of word learning takes place incidentally through exposure to new words in meaningful contexts. Implicit learning through meaning-focused reading can occur incidentally as a result of learners' engaging in such activities as integrated task sets (a series of tasks requiring the use of multiple skills), narrow reading, rereading, timed and paced readings, intensive and extensive reading (Hunt \& Beglar, 2005:15). Swanborn and Glopper (2002:98) also examine how reading texts for different purposes affects amounts of incidental word learning and then come to the conclusion that only the meaning of unknown words that are relevant for the reading purpose will be derived and recalled. Although these activities deserve greater attention in many EFL classrooms, the investigator intends to place emphasis upon extensive reading as the primary means for implicit learning because of its potentiality for triggering EFL learners and for the reason that it can take advantage of the amount of meaningful input accessible to learners.

\subsection{Extensive reading}

In extensive reading, learners select and read large amounts of materials that appeal them and are within their level of comprehension. The core of meaning-focused input strand of a course is a well-organized, well-monitored, substantial extensive reading programme ... (Nation \& Meara, 2002:40). Shu et al., (1995:79) highlight that learning from context through extensive reading might be one of the important sources in children's vocabulary growth. Intermediate and advanced L2 learners enlarge their vocabulary to a great extent through incidental learning during extensive reading (Hulstijn et al., 1996:337).

For extensive reading to be efficient, learners must be frequently exposed to bulky amounts of comprehensible text. Since the knowledge gained from a single encounter with a lexical item is likely to be disremembered unless rapidly followed by another encounter, repeated contextualized exposures are necessary to consolidate and secure word meaning. Harmon (1999:306) advocates the promotion of wide reading as an important vehicle for vocabulary development because students learn words from context during reading. Teachers can promote consolidation through the use of post-reading activities in which learners first 
notice the target lexis by highlighting, underlining or circling them, and then processing them by classifying, analyzing, or using the items productively (Hunt \& Beglar, 2005:9).

\subsubsection{Note-taking}

After getting information about a lexical unit, learners may take notes, in the form of vocabulary notebooks, vocabulary cards, or simply notes along the margins or between the lines (marginal glosses). Note-taking is one of the basic strategies often recommended by researchers in the field of vocabulary learning. Vocabulary cards are invaluable in consolidating primary gains because of their probability, ease of use and number of communicative activities in which they can be used, as well as their potentiality for increasing student's enthusiasm. In a comparative empirical research, Hulstijn et al. (1996:336) conclude that the effect of marginal glosses will be greater than that of dictionary use because readers often do not make use of the dictionary. However, they then refine their conclusion in a way that when readers do use dictionary, the incidence of incidental vocabulary learning will be as good as, or even better, when they are provided with marginal glosses.

\subsubsection{Mnemonics: Zeroing in on memory}

Among various other strategies frequently studied in the literature, one that requires a considerable amount of treatment and profound processing is the mnemonics. Since vocabulary learning is essentially a memory matter, therefore mnemonics should quest for foreign language vocabulary learning as well.

One of the most studies mnemonics is the keyword method, in which the foreign word is remembered by being linked to a keyword, a sound-like native word (the acoustic link), through an interactive image that involves both the foreign word and the native word (the imagery link). Avila and Sadoski (1996:380) define keyword method in two stages. First, the FL word is associated with a familiar concrete word (keyword) based on acoustic similarities. The next stage is the production of an imaginal link between the target word and the keyword.

Since in this method the linkages from the vocabulary to a meaningful definition are provided, they will produce enhanced associative recall of definitions. As a result, the mnemonics links, particularly the imagery keyword technique, enable learners to memorize vocabulary more effectively. One of the frequently quoted claims of mnemonics is that people remember better over long periods of time if they have utilized mnemonic aids because they have a way to "get back at the word again" (Ott et al., 1976:45).

Irrespective of the advantages of this method, there exist some limitations:

1. The mnemonic approach to vocabulary development emphasizes on a unchanging one-to-one relationship between form and meaning. However, a key view in the applied linguist's conception of vocabulary is manifold meanings and multiple dimensions of meanings (referential, syntactic, pragmatic, emotional, functional, literary, etc.).

2. Mnemonic devices are much less effective in productive vocabulary learning than in learning to comprehension the L2 because imagery association in the keyword technique 
allows retrieval of a keyword which is merely an approximation to L2 form $(\mathrm{Gu}$, 2003:15).

3. Mnemonic devices mainly aim for the retention of coupled-associates. However, the vocabulary of an L2 is far more than a collection of L1-L2 word couples.

\subsubsection{Word-formation: Focusing on form}

Knowledge of lexical roots (etymological information and morphological origins) can assist in vocabulary development in that it helps students predicate or guess what a word means, elucidate why a word is spelt the way it is, and remember the word by knowing how its current meaning develops from its morphological roots. Students should learn to identify morphemes which recur in a number of words and which can help them to identify at least part of the meaning, thus assisting them in guessing from context the meaning of apparently new items (Rivers, 1981:465). Contextual information and word morphology (e.g. word roots, affixes, and inflectional suffixes) are two major sources that readers use to interpret novel words (Mori, 2003:404).

Although most words can be decomposed into root words, prefixes, and suffixes, the degree to which these components specify the meaning of the whole varies widely. Shu et al. (1995:80) introduce two major categories of words. First, the meaning of some words can easily be determined on the basis of the word parts with little or no help from context (morphologically transparent words). Second, at the other extreme are words for which the components contribute almost nothing to the meaning (morphologically opaque words). In general, most words fall in between; although their meanings cannot be derived solely on the basis of word parts, their meanings are likely to be clear when they appear in even a moderately helpful context.

In this regard, two studies by Bogaards (2001:321) underscore the importance of knowledge of form -but not of previously learned meaning- for the learning of new meanings for familiar forms. He then based on his first experiment concludes that totally new single-word units are harder to learn and retain than multiword units of the same meaning but with a form that is made up of familiar words. In another technical study on the effects of semantic and structural elaboration on the second language (L2) lexical acquisition, Barcrof (2002:323) provides evidence that increased semantic elaboration (evaluation of an item with regard to its meaning) can inhibit one's ability to encode the formal [phonemic/graphemic] properties of new words. Still in an interesting experiment by Nagy, McClure and Mir (1997:431) state that first language syntactic knowledge influences guesses about the meanings of unfamiliar words in a second language context. This effect is found among bilinguals who have experienced a variety of amounts and types of exposure to English.

A learner needs three skills in order to make use of affixation: breaking a new word into parts so that the affixes and roots are revealed; knowing the meaning of the parts; and being able to connect the meaning of the parts with the meaning of the word. Put another way, to make use of word parts, the learner needs to know the most useful word parts of English (20 or so high-frequency prefixes and suffixes are enough initially), needs to be able to recognize them in their various forms when they occur in words and needs to be able to relate the meanings of the parts to the meaning of definition (Nation \& Meara, 2002:46). 


\subsection{Learner-dependent Vocabulary Learning Strategies}

From guessing at the first encounter, to possible dictionary use and note taking, to memorizing, encoding, and contextual activation, vocabulary acquisition is a dynamic process involving metacognitive choices and cognitive implementation of a whole spectrum of strategies. Whether and how a learner evaluates the task requirement and whether and how a cognitive strategy is utilized are often dependent more on the learner than on the task.

\subsubsection{Good Learners \& Poor Learners}

Researchers in VLS (vocabulary learning strategy) area have attempted to identify the ways in which "good" and "poor" learners approach lexical learning. The good learners are more aware of what they can learn about new words, pay more attention to collocation and spelling, and are more conscious of contextual learning. By contrast, the poor learners are generally characterized by their apparent passiveness in learning. Swanborn and Glopper (2002:99) suggest that poor readers are not as able as good readers at adjusting their reading strategies to fit the reading purpose and accordingly learning more affectively from context. In other words, good readers are accordingly good comprehenders and learners who are better skilled at handling vocabulary acquisition tasks. In a similar study, Pulido (2003:239) states that strong readers tend to have more efficient decoding skills and larger sight vocabularies than weak readers. So these outcomes in reading performance can be explained by individual differences and strategies applied in these areas. Gu and Johnson (1996:668) also studied 850 university EFL students in China, and tried to establish how different vocabulary strategies were related to language learning outcomes. Both Pearson's correlation and multiple regression analyses revealed that self-initiation, selective attention, and deliberate activation of newly learned words consistently predicted both vocabulary size and general proficiency. Other predictors of success included contextual learning, dictionary, and note-taking strategies.

\section{Methodology}

This study profiles those issues, strategies, techniques and variables related to vocabulary acquisition in detail. In other words, the investigator tries to expand on the concepts largely applied in the field of vocabulary knowledge and acquisition.

This paper also takes best advantage of other researchers' recent findings and achievements in the specific areas of vocabulary acquisition. Therefore, it attempts to present these major findings under each of the main areas of study on the topic. It is intended that the research zooms in critically on the variables connected to lexical knowledge and launches rather comprehensive framework considering and taking in mostly important strategies and factors within the vocabulary acquisition context.

The research specifically concentrates on the four variables: learner, task, context, and strategies from different dimensions regarding other's investigations and achievements. The investigator then tries to explain on major issues and comments concerning each variable. 


\section{Discussion}

In a rather comprehensive review of related literature, the factors and variables involved in vocabulary acquisition were critically discussed and analyzed. The crucial notion implied via critical understanding of the materials developed and argued in this study seems to point out the fact that in lieu of seeking the excellent strategies that create the best results, the investigator maintains the relative efficiency of each strategy. In addition, the organic notion underlying this study is that the most effective and efficient lexical development will occur in multifaceted curriculums that attain a pedagogically sound equilibrium between explicit and implicit activities for L2 learners at all levels of their development.

At last, in order to avoid explaining repeatedly very similar research findings already mentioned fully on various strategies and approaches to vocabulary acquisition, the researcher in the discussion part goes on to outline most important implications noted within the paper. Furthermore, it will touch on topics needed for future research.

a. The rough focus of research in the linguistics tradition regarding vocabulary acquisition has largely centered on vocabulary learning (what is learned/to be learned; productoriented view) rather than acquisition (how is vocabulary learned, process-oriented perspective)(Crow, 1986; Meara, 1980).

b. From a psychological standpoint, memory strategies have occupied the major share of attention in vocabulary acquisition, probably for the reason that this learning/ acquisition process has largely been taken to mean as a memory problem.

c. Much of the stress on incidental vocabulary learning has zeroed in on how helpful incidental learning is and how much can be learned incidentally, often ignoring the fact that a lot can be learned intentionally and by design during reading with the help of strategies (e.g. inferring from context, dictionary use, note-taking, as well as intentional repetition).

d. Accessible research on vocabulary learning strategies does refer to a direction that good learners act better that poor ones, but the field would definitely benefit from a clearer focus on how precisely learners learn lexical units and how their strategies are related to acquisition outcomes (Schmitt, 2000).

e. Research efforts have largely been directed towards discovering and supporting the best strategy for vocabulary retention. In reality, learners tend to utilize a variety of strategies in combination. Therefore, as highlighted in this paper, to search for designing a multifaceted framework with a pedagogically sound equilibrium taking advantage of the positive and appropriate strengths of each strategy in a due and sensible time and at relevant level seems highly preferable.

\section{Conclusion}

The primary goal of this study is to investigate and review the effects of learning strategies on EFL vocabulary acquisition during recent years. Vocabulary acquisition can be best conceived as a process in which L2 learners negotiate word meaning from a text level 
to a word level. This shift is necessary so that the learner can form a mental connection between the word form and his/her meaning premise (Mohseni-Far, 2006:162). Second language (L2) learners who use scaffolding strategies such as inferring word meanings through contextual clues and determining word meanings through dictionary reference stand to benefit.

Technically speaking, word knowledge includes the ability to recall meaning, infer meaning, comprehend a text, and communicate orally. No single approach can address all of these skills; when learners receive input about vocabulary only from reading or only from the use of lists, drills, or skill-building activities, they have not addressed the range of skills needed for word use. Effective approach to word learning should be multifaceted in what they require of the learner and rich in what they reveal about the target words. Put another way, most of the noted recent researchers came to this conclusion that the most efficient and practical learning approach involves a carefully selected combination of both explicit and implicit instruction and learning.

Word knowledge has linguistic, psycholinguistic, and sociolinguistic aspects. Lexical competence is far more than the ability to define a given number of words; it involves knowing a great deal about each word, including information about its general frequency of use, the syntactic and situational limitations on its use, its generilizability, its collocational probabilities, its underlying form, its derived forms, and its semantic features. The process by which learners acquire this information appears to take place gradually over a long period of time, is very complex, and is quite difficult to investigate. In conclusion, a lot of work has been done to find overall patterns of strategy use. However, the choice, use, and effectiveness of vocabulary learning strategies very much depend on the task (e.g. breadth vs. depth), the learner (e.g. cognitive and cultural styles of learning, motivation), and the context. Future research, therefore, needs a more technical and closer touch that takes all the previous aspects into account.

\section{Bibliography}

Avila, E. \& M. Sadoski (1996). Exploring new applications of the keyword method to acquire English vocabulary. Language Learning, 46, 379-395.

Barcrof, J. (2002). Semantic and structural elaboration in L2 lexical acquisition. Language Learning, 52, 323-363.

Bogaards, P. (2001). Lexical units and the learning of foreign language vocabulary. Studies in Second Language Acquisition, 23, 321-343.

Celce-Murcia, M. (2001). Teaching English as a Second or Foreign Language. United States of America: Heinle \& Heinle.

Chin, C. (1999). The effects of three learning strategies on EFL vocabulary acquisition. The Korea TESOL Journal, 2, 1-29.

Chun, D.M. \& J.L. Plass (1996). Effects of multimedia annotations on vocabulary acquisition. The Modern Language Journal, 80, 183-212.

Cook, V. (1991). Second Language Learning and Language Teaching. London: Edward Arnold.

Crow, J. T. (1986). Receptive vocabulary acquisition for reading comprehension. The Modern Language Journal, 70, 242-250.

De la Fuente, M.J. (2002). Negotiation and oral acquisition of L2 vocabulary. Studies in Second Language Acquisition, 24, 81-112. 
Ellis, R., Y. Tanaka \& A. Yamazaki (1994). "Classroom interaction, comprehension, and the acquisition of L2 word meanings". Language Learning, 44, 449-491.

Gu, Y. (2003). "Vocabulary learning in a second language". TESL-EJ, 7, 1-26.

Gu, Y. \& R.K. Johnson (1996). "Vocabulary learning strategies and language learning outcomes". Language Learning, 46, 643-679.

Harmon, J.M. (1999). "Initial encounters with unfamiliar words in independent reading". R.T.E., 33, 304-338.

Hulstijn, J.H., M. Hollander \& T. Greidanus (1996). "Incidental vocabulary learning by advanced foreign language students: the influence of marginal glosses, dictionary use, and reoccurrence of unknown words". The Modern Language Journal, 80, 327-339.

Hulstijn, J.H. \& B. Laufer (2001). "Some empirical evidence for the involvement load hypothesis in vocabulary acquisition". Language Learning, 51, 539-558.

Hunt, A. \& D. Beglar (2005). "A framework for developing EFL reading vocabulary". Reading in a Foreign Language, 17, 1-31.

Laufer, B. \& L. Hadar (1997). "Assessing the effectiveness of monolingual, bilingual, and "bilingualized" dictionaries in the comprehension and production of new words". The Modern Language Journal, 81, 189-196.

Laufer, B. \& J. Hulstijn (2001). "Incidental vocabulary acquisition in a second language: the construct of task-induced involvement". Applied Linguistics, 22, 1-26.

Lawson, M.J. \& D. Hogben (1996). "The vocabulary learning strategies of foreign language students". Language Learning, 46, 101-135.

Meara, P. (1980). "Vocabulary acquisition: a neglected aspect of language learning". Language Teaching and Linguistics Abstracts, 13, 221-246.

Mohseni-Far, M. (2006). "Techniques utilized for vocabulary acquisition". Language Forum, 32, $147-165$.

Mori, Y. (2003). "The roles of context and word morphology in learning new Kanji words". The Modern Language Journal, 87, 404-420.

Nagy, W., E.F. McClure \& M. Mir (1997). "Linguistic transfer and the use of context by SpanishEnglish bilinguals". Applied Psycholinguistics, 18, 431-452.

Nation, P. \& P. Meara (2002). "Vocabulary". In N. Schmitt (ed.), an Introduction to Applied Linguistics, 35-54. London: Arnold.

Newton, J. (2001). "Options for vocabulary learning through communication tasks". ELT, 55, 3037.

Ott, C.E., R.S. Blake \& D.C. Butler (1976). "Implications of mental elaboration for the acquisition of foreign language vocabulary". IRAL, XIV, 37-48.

Prince, P. (1996). "Second language vocabulary learning: the role of context versus translations as a function of proficiency". The Modern Language Journal, 80, 478-493.

Pulido, D. (2003). "Modeling the role of second language proficiency and topic familiarity in second language incidental vocabulary acquisition through reading". Language Learning, $53,233-284$.

Pulido, D. (2004). "The relationship between text comprehension and second language incidental vocabulary acquisition: a matter of topic familiarity". Language Learning, 54, 469-523.

Rivers, W.M. (1981). Teaching Foreign-Language Skills. Chicago: The University of Chicago Press.

Schmitt, N. (2000). Vocabulary in Language Teaching. Cambridge: Cambridge University Press.

Shu, H., R.C. Anderson \& H. Zhang (1995). "Incidental learning of word meanings while reading: a Chinese and American cross-cultural study". Reading Research Quarterly, 30, 79-95. 
Swanborn, M.S.L. \& K.D. Glopper (2002). "Impact of reading purpose on incidental word learning from context". Language Learning, 52, 95-117.

Zimmerman, C.B. (1997). "Do reading and interactive vocabulary instruction make a difference? an empirical study". TESOL Quarterly, 31, 121-140.

Acknowledgement: I would like to express my deep gratitude on Professor Ismail Baroudy's thought-provoking and continuous support, my dear professor to his constant guidance I am greatly indebted. I thank so much Professor Daniel Madrid and anonymous referee(s) for their meticulous evaluation and sincere attention toward my paper. Finally, a special thanks goes to Mrs. Rezvan Abol-Nejadian, B.A., for supporting my research and encouragement, I am also grateful to her for helping me complete the work successfully. 